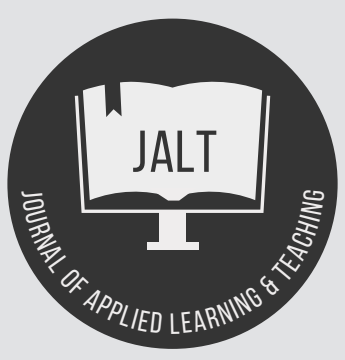

Vol 1 No $1(2018)$

Journal of Applied Learning \& Teaching

Content Available at : http://journals.sfu.ca/jalt/index.php/jalt/index

\title{
Lang, J. M. (2016). Small teaching. Everyday lessons from the science of learning. San Francisco: Jossey-Bass.
}

Jürgen Rudolph

Senior Lecturer and Academic Partner Liaison, Academic Faculty, Kaplan Higher Education Singapore

DOI: https://doi.org/10.37074/jalt.2018.1.1.9

James Lang's Small Teaching is one of my favourite books on teaching and learning in Higher Education. The activities described in the book are very appealing to me as they can be applied to multiple settings, from lecture theatres through all sorts of 'blended learning' all the way to a fully-online environment. Importantly, they are 'small', i.e. easy-to-prepare and not-so-time-consuming techniques, and they may be able to improve the effectiveness of one's teaching without engaging in a major review - not someday, but Monday. The suggested practices range from brief five to ten-minute activities, one-time interventions in a course to small modifications in course design or communication with students (pp. 7-8). The teaching and learning techniques described in Lang's highly practical and applicable book have their foundation in the interactive field of the learning sciences (including neuroscience and cognitive theory), and in addition, Lang also provides ample evidence for their positive impact in real-world higher education environments.

James Lang is a professor of English and director of the Center for Teaching Excellence at Assumption College, a small liberal arts college in Massachusetts. He is a prolific and well-known academic who, amongst many other things, writes a regular column for the Chronicle of Higher Education.

Lang's book is admirably well-organised. There are three main parts (Knowledge, Understanding and Inspiration) that are divided into three chapters each (that are cleverly titled with action verbs: Retrieving, Predicting, Interleaving, Connecting, Practicing, Self-Explaining, Motivating, Growing, and Expanding). Each chapter also has a substructure, comprising of the following elements: introduction, theory, models, principles, 'quick small teaching' and conclusion. The book's main sections are enveloped by an Introduction and a Conclusion. Excellent bibliographical references (that focus on key texts rather than on quantity) and a fairly detailed index are also included; and Chapter 9 contains a brilliant Resources section that, in addition to seminal books, contains web and Twitter resources for establishing one's own personal learning network (pp. 2358). While the book contains a highly practical collection of tips (especially in the 'quick small teaching' sections), it goes beyond them in offering a current and coherent framework.

In the first part of his book, Lang debunks a common misconception about Bloom's famous taxonomy of the cognitive domain that knowledge (or remembering) as being at the bottom of the hierarchy is less important and has been rendered less crucial by the omnipresence of Google searches. However, cognitive science research has shown that the so-called higher level activities (such as analysis and critical thinking) require extensive factual knowledge (p. 15).

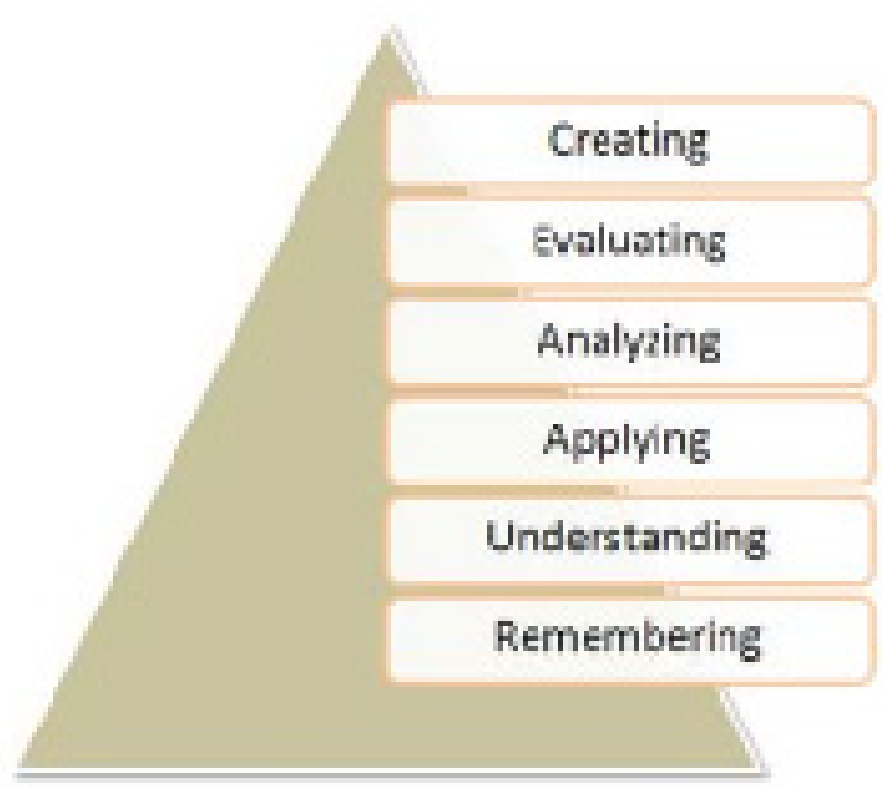

Figure 1: Bloom's cognitive domain (Clark, 2015).

The first chapter on Retrieving cites the powerful impact of brief multiple-choice quizzes (MCQs), for instance at the beginning and at the end of classes, in raising the grades 
of students (especially if such MCQs form eventually part of a summative assessment), as such retrieval practice strengthens and improves our memory. This can be done with 'clickers' as the lecturer can then also gauge the understanding of the students. Another intriguing recommendation (out of many others) by Prof Lang is to have a brief retrieval practice at the start of a class, where students write down what they recall from the previous class, and some of the recollections are then briefly discussed.

The second chapter discusses Predicting (incorporating pretesting). Intriguingly, Lang is able to cite research that concludes that "giving students a pretest on topics to be covered in a lecture improves their ability to answer related questions about those topics on a later final exam" (Carey, quoted in Lang, p. 45). Unlike a computer, our brain works with networked knowledge, embedding facts, ideas and experiences in networks of perceptions, facts and thoughts. Unsuccessful attempts at problem-solving may encourage deep processing of an answer, and curious minds exhibited an increase in activity in the horseshoeshaped hippocampus which is involved in the creation of memories.

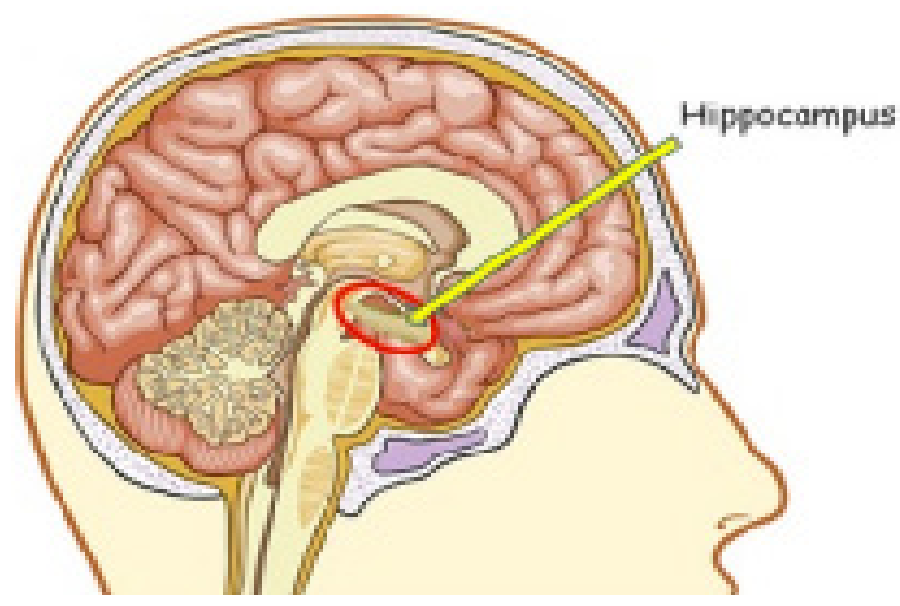

Figure 2: Hippocampus (Jones, n.d.).

Interleaving, the topic of the third chapter, promotes longterm retention in all areas of learning by spacing out learning sessions over time and "mixing up" the practice of skills that we seek to develop (p. 65). Interleaving can, for instance, refer to spending time learning one thing, then learning a second thing before having quite mastered that first thing, then returning to the first thing, and then moving onto a third thing (p. 68). In order to achieve cumulative learning, every major assignment should require students to draw, at least to some extent, on skills or knowledge that they have learned in previous modules (p. 75). In keeping it 'small' and 'frequent', learners ideally would have the opportunity to return to key course concepts or skills multiple times over the course of a term, both in class and in their assessments (p. 82).

The second part of the book is titled "Understanding" which is equivalent to the second level of Bloom's taxonomy of the cognitive domain that we referred to earlier. Students' knowledge could consist of "small disconnected islets" (Orwell, quoted in Lang, p. 92) and may be sparse and superficial as they lack connections and
"Our brains are filled with cells called neurons, which do the work of what we call thinking. A human brain has at least 100 billion neurons, and those neurons contain branching structures called axons that allow them to communicate with other neurons" (p. 94).

In order to facilitate understanding and connecting, students could spend five minutes at the beginning of a class writing down what they think that they already know about a topic, and then the lecturer could spend another five minutes soliciting some responses to discuss them ( $p$. 101). Mind maps may also help with that.

Lang also highlights the importance of Practicing in a separate chapter. The Goldilocks principle that Lang recommends for student presentations may be also applicable to lecturers: presenters "should clearly reference and highlight the key components of what they have put on the slide, but not simply read it out directly" (p. 130). Having sat through disastrous student presentations and monotonous lectures - this is meaningful advice. Ideally, class time should also be used for practice, as repetition helps us master cognitive tasks such as speaking confidently in front of an audience.

Chapter 6 is devoted to Self-Explaining. An example is the teaching strategy of peer instruction that has been made famous by Harvard physicist Eric Mazur. For instance, the instructor projects a problem onto the classroom screen; the students record their answers with the help of 'clickers' and the instructor can view the answers on her screen; students then turn to a neighbour and explain their answer; students can then resubmit their answer; finally, a few students explain their answers and the instructor provides the correct answer (p. 153).

Motivation and attitudes play a crucial role, and inspiration (to which the third part of the book is dedicated) is critically important for both students and teachers. In chapter 7 (titled Motivating), Lang cites research "that the most powerful forms of purposefulness arise when students see the ability of their learning to make the world a better place" (p. 175). Another key insight is that emotional connections provide strong motivation. Thus, what really matters in one's university studies, "is who meets whom, and when" (Chambliss \& Takacs, 2014, cited in p. 177) - as we are social animals and feed off one another's emotions. As a consequence, the learning motivation of one's students can be improved by telling great stories; invoking purpose; sharing one's enthusiasm; and showing compassion.

Chapter 8 has the title "Growing". According to the research quoted by Lang, it is preferable to praise students for effort rather than praising their ability. The former motivates students to work harder and improves their tenacity. While our potential is not unlimited, we have more capacity for lifelong learning and brain development than what was previously thought (p. 201). Thus, written feedback on assignments should, for instance, read "You have obviously worked very hard at your writing, and it shows in this essay" rather than "You are a talented writer" (p. 209). Teachers can help change mindsets. 
After the previous eight chapters focused on numerous 'small teaching' strategies, Chapter 9 (Expanding) briefly discusses 'big teaching' and offers some inspiring examples of activity-based learning, such as the creation of a microloan programme in the Philippines.
In conclusion, Lang's book is humourous and inspiring as it shows that small steps can make a big difference. I look forward to experimenting more with some of the strategies in my own teaching. In using personal examples from his five children and his university teaching, sports analogies as well literary quotes, Lang provides an excellent resource to lecturers and tutors involved in higher education, and I highly recommend this gem of a book.

\section{References}

Carey, B. (2014). How we learn. The surprising truth about when, where, and why it happens. New York, NY: Random House.

Chambliss, C. F., \& Takacs, C. J. (2014). How college works. Cambridge, MA: Harvard University Press.
Clark, D. R. (2015). Bloom's taxonomy of learning domains. Retrieved from http://www.nwlink.com/ donclark/hrd/ bloom.html

Jones, S. (n.d.). The brain made simple. Retrieved from http://brainmadesimple.com/hippocampus.html

Orwell, G. (1986). A clergyman's daughter. London, UK: Penguin Books.

Copyright: @ 2020 Jürgen Rudolph. This is an open-access article distributed under the terms of the Creative Commons Attribution License (CC BY). The use, distribution or reproduction in other forums is permitted, provided the original author(s) and the copyright owner(s) are credited and that the original publication in this journal is cited, in accordance with accepted academic practice. No use, distribution or reproduction is permitted which does not comply with these terms. 